\title{
Effects of Steaming, Microwaving, and Hot-Air Drying on the Physicochemical Properties and Storage Stability of Oat Bran
}

\author{
Xue Bai (iD, Mei-Li Zhang (iD, Yuanyuan Zhang, Jing Zhang, Yakun Zhang, Chen Wang, \\ and Ruirui Liu
}

Inner Mongolia Agricultural University, College of Food Science and Engineering, Hohhot 010018, China

Correspondence should be addressed to Mei-Li Zhang; zhangmeili22@sina.com

Received 24 April 2021; Accepted 10 June 2021; Published 1 July 2021

Academic Editor: Antimo Di Maro

Copyright (c) 2021 Xue Bai et al. This is an open access article distributed under the Creative Commons Attribution License, which permits unrestricted use, distribution, and reproduction in any medium, provided the original work is properly cited.

\begin{abstract}
Oat bran is a nutrient-dense, resource-rich byproduct that is produced from oat milling. Oxidative deterioration is the main reason that limits the utilisation of oat bran. Thus, improving the storage stability of oat bran has become an urgent requirement. This study aimed to investigate the inhibition of oat bran deterioration via steaming, microwaving, and hot-air drying treatments and the effects of these methods on oat bran physicochemical properties and storage stability. Results indicated that, after the three heating treatments, the solubility of oat bran increased and the powder fluidity showed no significant change $(P<0.05)$. Steamtreated oat bran demonstrated increased initial gelatinisation temperature, peak temperature, and enthalpy, significantly reduced peak viscosity, trough viscosity, breakdown value, final viscosity, and setback value, and significantly improved thermal stability $(P<0.05)$. During accelerated storage, oat bran samples subjected to the three heat treatments showed increased sensory scores and $L^{*}, a^{*}$, and $b^{*}$ values, whereas due to the decrease of lipase activity in oat bran, their fatty acid values and malondialdehyde content increased slowly and were always lower than those of unprocessed oat bran. All three heat treatments could improve the storage stability and the quality deterioration of oat bran during storage due to oil oxidation. Steaming had the most significant effect.
\end{abstract}

\section{Introduction}

Cereals can be considered rich sources of soluble fibres, oligosaccharides, and resistive starch [1]. Cereal bran is a good source of vitamins and other nutrients. Oat bran, a byproduct of grain processing, is widely used for the enrichment of dietary fibres, especially insoluble dietary fibre $[2,3]$. Oat bran contains $18.1-25.2 \mathrm{~g} / 100 \mathrm{~g}$ total dietary fibre, which mainly comprises insoluble dietary fibre, and 3.6-5 g/ $100 \mathrm{~g}$ soluble dietary fibre [4]. Moreover, oat bran is rich in dietary lipids, proteins, starches, oligosaccharides, $\beta$-glucan, and polysaccharides. It has probiotic effects and is also recognised for its anticancerous and hypocholesterolemia properties [5].

A previous study showed the potential for a new fermentable oat-based beverage with functional quality considering the high levels of phenolic compounds and nutritional properties of oat bran extract combined with the health properties of probiotic bacteria [6]. The effectiveness of oat bran supplementation in improving triglyceride, total cholesterol, and HDL-cholesterol levels suggests that this approach is a therapeutic option for cardiovascular risk control in patients with psychiatric disorders [7].

Despite the many health-related benefits of oat bran, the high susceptibility of oat bran to oxidation and deterioration greatly affects storage life and eating quality [8]. Some challenges in using oat bran as a food product remain. The rapid deterioration of oat bran limits the shelf life of this material. Generally, oat bran is much higher in lipids and has higher lipase activity than oats. Fat is sensitive to deterioration via lipolysis and to oxidative rancidity [9]. Oat bran contains a large amount of fat, which is rapidly hydrolysed by temperature, oxygen, and water activity to produce free fatty acids and further oxidised into small molecules, such as aldehydes, ketones, and acids; these substances eventually cause the poor flavour and functional quality of oat bran [4]. 
Therefore, expanding the research on improving oat bran quality and storage stability is beneficial for reducing the loss during oat bran storage and processing and expanding the utilisation of oat bran resources. Steaming, microwaving, and hot-air drying are common processing methods for inhibiting the oxidative rancidity of grains. Steaming is a physical modification technique that generally involves inducing changes in the physicochemical properties of a material without affecting the molecular structure under certain moisture volume fractions and temperature range conditions [10]. Steaming has the advantages of environmental friendliness, high efficiency, and low cost. Moist-heat treatment can inactivate peroxidases (PODs) and lipases in wheat bran, thus resulting in lower peroxide values and higher unsaturated fatty acid content and sensory evaluation scores of steam-treated samples than those of hot-air-dried samples [11]. Microwave action on polar molecules in materials causes intense internal friction and generates heat energy with high heating efficiency. Microwave treatment partially inactivates lipase in flour, thus hindering the oxidation of free fatty acids [12]. Hot-air drying involves the use of hot air to heat materials and is mainly used to dry agricultural products. The stability of flour is significantly improved after hot-air drying [13]. However, until now, the application of the above treatments to stabilise fat in oat bran has not been studied.

In this work, the effects of three heat treatments, namely, steaming, microwaving, and hot-air drying, on the solubility, powder flow, pasting characteristics, thermodynamic properties, and storage stability of oat bran were investigated. The effects of different heat treatments on the physical properties and storage stability of oat bran were investigated to provide theoretical data references for the processing and utilisation of oat bran. Choosing the optimal method for processing oat bran and improving storage stability will be helpful for controlling quality, extending shelf life, and improving the sensory acceptability of the final products.

\section{Materials and Methods}

2.1. Materials. Raw oat bran (OB), an industrial byproduct, was obtained from Inner Mongolia Xibei Huitong Agricultural Technology Development Co., Inner Mongolia, China.

\subsection{Methods}

2.2.1. Stabilisation of $O B$. OB was sieved through a 60 -mesh screen and then treated via different stabilisation methods. $\mathrm{OB}$ was stabilised by using a steamer at $100^{\circ} \mathrm{C}$ for $20 \mathrm{~min}$, a domestic microwave at $800 \mathrm{~W}$ for $2 \mathrm{~min}$, and a GZX-9076 $\mathrm{MBE}$ hot-air oven at $140^{\circ} \mathrm{C}$ for $15 \mathrm{~min}$ (Medical equipment factory of Shanghai bosun Industrial Co., Ltd., China). Subsequently, the oat bran samples that had been stabilised through the three different methods were cooled down on a cooling tray for approximately $40 \mathrm{~min}$ to room temperature and stored in a refrigerator at $-20^{\circ} \mathrm{C}$.
2.2.2. Storage and Testing. The experimental samples prepared through different heat treatments were weighed and placed in a constant temperature and -humidity incubator at $50^{\circ} \mathrm{C} \pm 2^{\circ} \mathrm{C}$ for accelerated oxidation. All samples were stored for up to 8 weeks. Each group of samples was divided equally into nine independent copies $\left(100 \mathrm{~g} \mathrm{copy}^{-1}\right)$ for determination each week and then transferred to a refrigerator at $-20^{\circ} \mathrm{C}$ for subsequent analysis. Each analysis was carried out in triplicate, and the mean value was calculated and used in further analysis. OB was also stored for comparison.

\subsubsection{Physicomechanical Attributes}

Dissolving Properties. Dissolving properties were analysed in accordance with the method of Benhur Dayakar Rao [14].

Powder Fluidity. Volume density was measured by accurately weighing a $20 \mathrm{~g}$ sample in a $100 \mathrm{~mL}$ measuring cylinder. The cylinder was gently tapped on the table for 10 times, and the scale value $(V)$ after tapping was recorded. This measurement was repeated three times. The Carr index and Hausner ratio were measured by weighing a $10 \mathrm{~g}$ sample. The sample was then loaded into a $25 \mathrm{~mL}$ measuring cylinder. The initial volume $V 1$ was read, and the final volume $V 2$ was read after tapping until the powder reached its most compact state.

$$
\begin{aligned}
\text { Volume density }(\mathrm{g} / \mathrm{mL}) & =\frac{20}{V}, \\
\mathrm{CI}(\%) & =\frac{(1 / V 2)-(1 / V 1)}{(1 / V 2)} \times 100, \\
\mathrm{HR} & =\frac{V 1}{V 2} .
\end{aligned}
$$

Gelatinisation Property. The sample was accurately weighed in the measuring cylinder, prepared into a suspension with $8 \%$ mass fraction, stirred evenly, and placed in the measuring instrument. The program was set as follows: the temperature was raised from $50^{\circ} \mathrm{C}$ to $95^{\circ} \mathrm{C}$ at the rate of $5^{\circ} \mathrm{C} /$ min. The temperature was then maintained for $10 \mathrm{~min}$. Subsequently, the temperature was reduced to $50^{\circ} \mathrm{C}$ at a rate of $5^{\circ} \mathrm{C} / \mathrm{min}$ and held for $10 \mathrm{~min}$. Parameters, such as peak viscosity (PV), trough viscosity, breakdown value, and final viscosity (FV), were analysed by using the measured viscosity curves.

Thermodynamic Property. Firstly, standard indium was used to calibrate the DSC instrument. A total of 3-5 mg of oat bran was placed in a PE crucible and heated from $40^{\circ} \mathrm{C}$ to $200^{\circ} \mathrm{C}$ at a rate of $10^{\circ} \mathrm{C} / \mathrm{min}$. The empty crucible was used as a reference. The carrier gas was nitrogen, and its flow rate was $20 \mathrm{~mL} / \mathrm{min}$. The enthalpy value $(\Delta H)$, initial gelatinisation temperature $\left(T_{0}\right)$, and peak temperature $\left(T_{\mathrm{P}}\right)$ were calculated. 


\subsubsection{Storage Stability Determination}

Free Fatty Acid Content. The FFA content was determined by AOCS official method Ca 5a-40 [15].

Malondialdehyde. Malondialdehyde (MDA) was determined and analysed as the method of Johnston et al. [16].

Sensory Evaluation. Sensory evaluators consisted of five people who had been trained and had experience in similar evaluations. Before receiving a brief single training session in the formal experiment, the evaluation personnel (18-24 years old) were familiar with a variety of references and might thus present diverse flavour vocabularies. For sensory analysis, the samples were labelled by using random threedigit numbers and presented in a randomised order. A 0-5point scale with a reference was used for sensory evaluation. A $20 \mathrm{~g}$ sample was taken, placed in a jar, transferred to a $50^{\circ} \mathrm{C}$ water bath pot, and covered with a cork. The sample was incubated for $5 \mathrm{~min}$ then opened and sniffed. The minimum value was 0 (no off-flavour) and the maximum value was 5 (very intense off-flavour).

Colour parameters $\left(L^{*}, a^{*}\right.$, and $\left.b^{*}\right)$ were measured on different points on the surfaces of the samples. The colour of the samples was measured by using a tristimulus colorimeter (CR-400 Chroma Meter, Konica Minolta Sensing, Osaka, Japan) as described by Kayitesi et al. [17]. Colour was expressed in terms of lightness $\left(L^{*}\right)$, red/green $\left(a^{*}\right)$, and blue/yellow characteristics $\left(b^{*}\right)$ after standardisation with a white tile supplied by the manufacturer. $L^{*}, a^{*}$, and $b^{*}$ equation (1) values over storage time were compared with the values of the baseline untreated control $\left(\mathrm{U}_{0}\right)$ and calculated as $\Delta L^{*}=L^{*}-\mathrm{L}_{\mathrm{U} 0}, \Delta a^{*}=a^{*}-\mathrm{a}_{\mathrm{U} 0}$, and $\Delta b^{*}=b^{*}$ $-b_{\mathrm{U} 0}$, where $L_{\mathrm{U} 0}, a_{\mathrm{U} 0}$, and $b_{\mathrm{U} 0}$ are the colour component values of the untreated control $U$ at week 0 . The total colour difference $(\Delta E)$ between the test porridges and the $\mathrm{U}_{0}$ control was calculated as $\Delta E=\left[\left(\Delta L^{*}\right)^{2}+\left(\Delta a^{*}\right)^{2}+\left(\Delta b^{*}\right) 2\right]^{1 / 2}$.

2.3. Statistical Analysis. SPSS Statistics 26 was used for data processing and analysis. All tests were carried out in triplicate, and the data were presented as the mean \pm standard deviation. One-way ANOVA was used to detect the difference between mean values, with $P<0.05$ indicating significant difference. Origin 2018 drawing software was used to generate the related graphs.

\section{Results and Discussion}

3.1. Effect of Different Heat Treatments on the Solubility and Powder Flow of Oat Bran. The water solubility index (WSI) reflects the degradation degree of starch, protein, and cellulose in oat bran, and a high WSI indicates that oat bran is easily digested and absorbed by the body when consumed. The water absorption index (WAI) is a measure of the ability of the starch in the grain to form a gel when it swells with water [18]. As shown in Table 1, compared with the unprocessed samples, the samples subjected to steam, microwave, and hot-air drying treatments showed increases in
WSI of $11.70 \%, 26.32 \%$, and $19.01 \%$, respectively, and increments in WAI of $7.06 \%, 9.08 \%$, and $6.22 \%$, respectively. These results indicated that all three processing treatments significantly increased the solubility of oat bran $(P<0.05)$. During starch pasting, microcrystalline starch grain bundles disintegrate, hydrogen bonds within the molecules break, and the starch grain structure loosens and easily binds to water [19]. These effects increased the WAI of oat bran after pretreatment. Consistent with the results of this study, the results reported by $\mathrm{Hu}$ [20] showed that the WSI and WAI of rice bran after superheated steam treatment have increased compared with those before pretreatment.

The Carr index and Hausner ratio reflect the flow characteristics of powders under compression. They are important properties to be considered for the reconstitution, transport, and packaging of powders [21]. Significant reductions in the Carr index and Hausner ratio reflect improvements in powder fluidity [22]. The powder CI and HR were in the ranges of 37.63-42.9 and 1.60-1.75, respectively.

The Carr index and Hausner ratio of S-OB, M-OB, and $\mathrm{HA}-\mathrm{OB}$ were not significantly different from those of the raw samples $(P<0.05)$, indicating that the three processing methods did not significantly change the fluidity of the powder. The bulk density of HA-OB was significantly lower than that of $\mathrm{OB}(P<0.05)$. The reduction in bulk density may also be due to surface hardening at high temperatures [23].

3.2. Effects of Different Processing Methods on the Gelatinisation Properties of Oat Bran. As shown in Table 2, the peak viscosity, trough viscosity, and breakdown values of oat bran significantly decreased $(P<0.05)$ after steaming treatment and significantly increased $(P<0.05)$ after microwaving and hot-air drying treatments. The final viscosities of S-OB and $\mathrm{HA}-\mathrm{OB}$ were significantly lower than those of the other samples, whereas the final viscosities of $\mathrm{W}$-OB were significantly higher than those of other samples. The setback values of oat bran were significantly reduced $(P<0.05)$ after all three heat treatments.

Peak viscosity characterises the maximum swelling of starch granules before breakage and is also the equilibrium point between the swelling and breakage of starch granules; granules with high peak viscosity have weak adhesion to other granules and are likely to break [24]. Final viscosity reflects the ability of starch molecules to rearrange to form a gel during cooling after pasting. The changes in the peak and final viscosities of S-OB indicated that steam treatment can lead to the increased internal binding of oat bran; this effect promoted the maintenance of good properties under external forces but decreased gelation capacity.

The breakdown value is related to the strength of the starch granules after expansion and reflects the stability of the starch paste. A small breakdown value indicates the good stability of the thermal paste. The breakdown value of S-OB was significantly lower than that of unprocessed oat bran $(P<0.05)$. This result indicates that the steaming treatment significantly improved the stability of oat bran $(P<0.05)$. 
TABLE 1: Solubility and powder fluidity of oat bran after different heat treatments.

\begin{tabular}{lccccc}
\hline Sample & WSI\% & WAI & Bulk density $(\mathrm{g} / \mathrm{mL})$ & Carr index & Hausner ratio \\
\hline OB & $3.42 \pm 0.34 \mathrm{~b}$ & $5.95 \pm 0.09 \mathrm{~b}$ & $0.34 \pm 0.00 \mathrm{a}$ & $37.63 \pm 1.98 \mathrm{a}$ & $1.60 \pm 0.05 \mathrm{a}$ \\
S-OB & $3.82 \pm 0.57 \mathrm{a}$ & $6.37 \pm 0.16 \mathrm{a}$ & $0.34 \pm 0.01 \mathrm{a}$ & $39.53 \pm 0.47 \mathrm{a}$ & $1.65 \pm 0.01 \mathrm{a}$ \\
M-OB & $4.32 \pm 0.59 \mathrm{a}$ & $6.49 \pm 0.25 \mathrm{a}$ & $0.34 \pm 0.02 \mathrm{a}$ & $41.02 \pm 2.31 \mathrm{a}$ & $1.70 \pm 0.07 \mathrm{a}$ \\
HA-OB & $4.07 \pm 0.24 \mathrm{a}$ & $6.32 \pm 0.22 \mathrm{a}$ & $0.33 \pm 0.01 \mathrm{~b}$ & $42.90 \pm 0.04 \mathrm{a}$ & $1.75 \pm 0.00 \mathrm{a}$ \\
\hline
\end{tabular}

Means within the same column that do not share a superscript letter or letter differ significantly $(P<0.05)$.

TABLE 2: Effects of different processing methods on the gelatinisation properties of oat bran.

\begin{tabular}{lccccc}
\hline Sample & Peak viscosity (MPa $\cdot$ s) & Trough viscosity (MPa $\cdot$ s) & Breakdown $(\mathrm{MPa} \cdot \mathrm{s})$ & Final viscosity $(\mathrm{MPa} \cdot \mathrm{s})$ & Setback $(\mathrm{MPa} \cdot \mathrm{s})$ \\
\hline OB & $827.00 \pm 48.00 \mathrm{~b}$ & $723.50 \pm 8.50 \mathrm{~b}$ & $103.5 \pm 39.5 \mathrm{c}$ & $1518.00 \pm 8.6 \mathrm{a}$ & $794.5 \pm 77.5 \mathrm{a}$ \\
S-OB & $733.50 \pm 27.50 \mathrm{~b}$ & $642.24 \pm 24.00 \mathrm{c}$ & $91.5 \pm 1.5 \mathrm{c}$ & $805.5 \pm 17.5 \mathrm{c}$ & $163.5 \pm 6.5 \mathrm{c}$ \\
W-OB & $1064.00 \pm 4.00 \mathrm{a}$ & $860.9 \pm 8.5 \mathrm{a}$ & $203.1 \pm 4.5 \mathrm{a}$ & $1704.75 \pm 45.75 \mathrm{a}$ & $843.85 \pm 37.25 \mathrm{a}$ \\
HA-OB & $1000.00 \pm 5.89 \mathrm{a}$ & $864.5 \pm 6.5 \mathrm{a}$ & $135.5 \pm 6.9 \mathrm{ab}$ & $1313.00 \pm 15 \mathrm{~b}$ & $448.50 \pm 21.50 \mathrm{~b}$ \\
\hline
\end{tabular}

Means within the same column that do not share a superscript letter or letter are significantly different $(P<0.05)$.

Compared with other samples, W-OB and HA-OB showed significantly larger values $(P<0.05)$, indicating that their thermal stability had weakened.

The setback value indicates the stability of the cold paste viscosity of starch, and high setback values indicate poor cold paste stability and reflect the reconjugation and crystallisation of starch molecules during starch cooling. This value is thus a reflection of the ageing nature of starch. As can be seen from Table 2, after heat treatment, the setback values of S-OB and HA-OB had decreased significantly $(P<0.05)$, whereas the setback value of $\mathrm{M}-\mathrm{OB}$ had increased significantly $(P<0.05)$. The setback value of S-OB was the lowest, indicating that, after heat treatment, S-OB showed enhanced cold stability and was difficult to age after heating and cooling. The effects of S-OB were more pronounced with the increase in amylose content [25]. Smith [26] reported that rough rice should be soaked at temperatures slightly below the onset gelatinisation temperature of the rice cultivar and steamed for $10 \mathrm{~min}$ to obtain the optimal gelatinisation properties. The changes described above improved the stability of oat bran. This effect is highly favourable for food production.

\subsection{Effects of Different Processing Methods on the Thermal} Properties of Oat Bran. $T_{0}, T_{\mathrm{P}}$, and enthalpy of pasting of oat bran after steaming treatment showed an increasing trend (Table 3). $T_{0}$ is a measure of the degree of crystallisation, and an increase in $T_{0}$ indicates the highly orderly crystallisation of oat bran after heat treatment $[27,28]$. The change in $T_{\mathrm{P}}$ is related to the degree of interaction between straight-chain and branched starches, with high $T_{\mathrm{p}}$ reflecting a stable starch structure [29]. As shown in Table 3, the initial pasting temperatures of oat bran subjected to different heat treatments were significantly increased, indicating that this parameter was greatly affected by different treatments. $T_{0}$ and $T_{\mathrm{P}}$ of S-OB had increased by $29.43^{\circ} \mathrm{C}$ and $90.62^{\circ} \mathrm{C}$, respectively, relative to that of $\mathrm{OB}$. Consistent with the change in disintegration values, the thermal stability of oat bran was significantly higher.

The increase in enthalpy $\Delta \mathrm{H}$ was likewise related to changes in the internal double helix structure of the starch
TABLE 3: Effects of different processing methods on the thermal properties of oat bran.

\begin{tabular}{lccc}
\hline Sample & $T_{0}\left({ }^{\circ} \mathrm{C}\right)$ & $T_{\mathrm{p}}\left({ }^{\circ} \mathrm{C}\right)$ & $\Delta H_{\text {gel }}(\mathrm{J} / \mathrm{g})$ \\
\hline OB & $42.67 \pm 5.64 \mathrm{c}$ & $20.70 \pm 4.9 \mathrm{c}$ & $73.41 \pm 0.9 \mathrm{~b}$ \\
S-OB & $72.10 \pm 10.7 \mathrm{~b}$ & $111.32 \pm 1.02 \mathrm{~b}$ & $143.77 \pm 2.87 \mathrm{a}$ \\
W-OB & $76.95 \pm 3.5 \mathrm{~b}$ & $106.32 \pm 3.02 \mathrm{~b}$ & $62.13 \pm 1.43 \mathrm{c}$ \\
HA-OB & $116.00 \pm 3.40 \mathrm{a}$ & $144.30 \pm 2.00 \mathrm{a}$ & $38.47 \pm 2.43 \mathrm{~d}$ \\
\hline
\end{tabular}

Means within the same column that do not share a superscript letter or letter differ significantly $(P<0.05) ; T_{0}$ : onset temperature; $T_{\mathrm{p}}$ : peak temperature; $\Delta H_{\text {gel }}$ : enthalpy of gelatinisation.

granules [30]. After different pretreatments, $\Delta H$ increased by $48.94 \%$ for S-OB and decreased by $15.37 \%$ and $47.60 \%$ for $\mathrm{M}-\mathrm{OB}$ and $\mathrm{HA}-\mathrm{OB}$, respectively. The higher enthalpy of pasting of the S-OB might be attributed to the capability of wet heat treatment to destroy the crystal structure of starch and strengthen the intermolecular interactions to form an ordered structure (helical structure or crystal structure) with increased thermal stability; that is, the ordered structure of molecules was rearranged and reoriented, resulting in the improvement in the thermal stability, double helical structure, and crystallinity of starch. By contrast, $\Delta H$ of $\mathrm{M}-\mathrm{OB}$ and HA-OB decreased, indicating that the heat treatment weakened the double helix structure of starch and decreased the energy required to unwind the helixes.

\subsection{Effect of Different Processing Methods on the Storage Stability of Oat Bran}

3.4.1. Changes in Free Fatty Acid Values during Storage by Oat Bran Subjected to Different Processing Methods. Fatty acid values are closely related to the free fatty acid content in food. The hydrolysis of oat bran fat under the action of lipase to produce free fatty acids is the main cause of rancidity and deterioration. The changes in fatty acid values during 56 days of accelerated storage at $50^{\circ} \mathrm{C}$ shown by oat bran samples subjected to different heat treatments are shown in Figure 1. During storage, the free fatty acid values of the oat bran samples processed through the three 


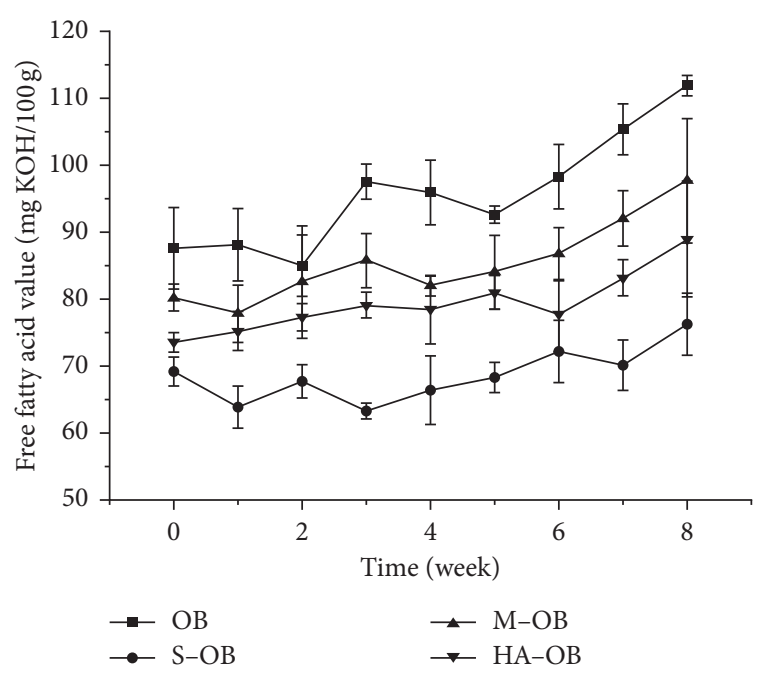

FIGURE 1: Changes in fatty acid values during storage by oat bran subjected to different pretreatment methods.

heat treatment methods were always lower than those of untreated samples. The fatty acid values of the oat bran that underwent moist-heat treatment fluctuated during storage.

The trend of the fatty acid values of $\mathrm{M}-\mathrm{OB}$ and $\mathrm{HA}-\mathrm{OB}$ during storage was similar to that of unprocessed OB. Specifically, they fluctuated upwards from days 0 to 21 , decreased from days 21 to 35 , and increased up to day 56 . The fatty acid values of $\mathrm{M}-\mathrm{OB}$ and $\mathrm{HA}-\mathrm{OB}$ increased by $22 \%$ and $17 \%$, respectively, whereas those of $\mathrm{OB}$ increased by $32 \%$, indicating that the storage stability of M-OB and HA-OB was superior to that of the unprocessed oat bran. A previous study showed that, during storage, the changes in the FFA, AV, and PV of rice bran after microwave treatment are stable and less than those of rice bran before processing [31]. Another work demonstrated that superheated steam is effective in suppressing the production of sour flavours and increasing fatty acid values during storage [32]. Hot-air drying is effective in suppressing rice bran rancidity [33]. The results of these studies are similar to those of the present study, demonstrating that the three thermal treatment methods were effective in reducing the activity of enzyme and improving the storage stability of oat bran and that the capability of steaming treatment to reduce the increase in fatty acid values during storage was more significant than that of the other treatments.

Therefore, steaming treatment can effectively inactivate enzymes, which is in agreement with the findings reported by Rose et al. [34] because proteins are more easily to denature in hot and humid environment.

3.4.2. Changes in MDA Values during Storage by Oat Bran Subjected to Different Processing Methods. The content of MDA, one of the degradation products of peroxides, can be used to measure the degree of lipid oxidation [35]. As seen in Figure 2, during 56 days of accelerated storage, all three heattreated oat bran samples had lower MDA content than OB. The MDA content of $\mathrm{OB}$ and oat bran processed through microwaving and hot-air drying showed similar trends

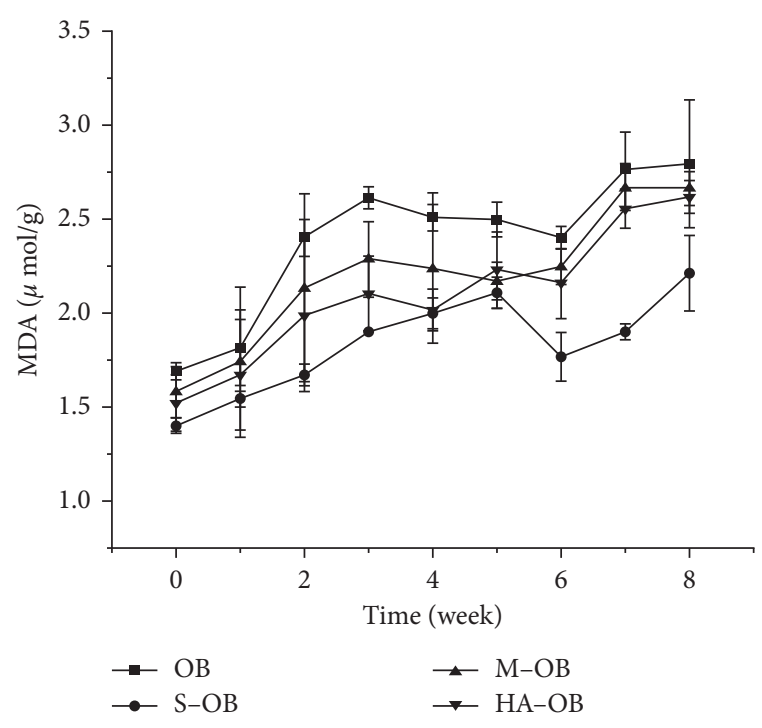

FIgURE 2: Changes in MDA values during storage by oat bran subjected to different heat treatments.

shown during the 56-day storage period. Specifically, they increased from days 0 to 21 , decreased from days 21 to 42 , and increased up to day 56.

During accelerated storage, free fatty acids accumulate in large quantities, followed by the activation of fat oxidase and the oxidation of fat to produce hydroperoxides [36], and malondialdehyde as its cleavage product begins to accumulate, so the malondialdehyde content increases. As storage time increases, the enzymatic activity of oat bran is gradually lost, which slows down the production of malondialdehyde, and the continuous high temperature causes some of the malondialdehyde to evaporate, resulting in a decrease in its content. MDA content also fluctuated during storage.

Combining these results with Figure 1 showed that the trend of fatty acid value was closely related to the change in MDA content, which was also the inevitable result of the nature of MDA as an intermediate product of lipid oxidation. The oat bran samples treated through microwaving and hot-air drying had slightly lower MDA contents than $\mathrm{OB}$ during storage, whereas the MDA content of steam-treated oat bran increased slowly during storage and remained at the lowest level. Comparing the three heat treatment methods showed that microwaving and hot-air drying did not have a significant effect on stabilising oat bran, whereas steam treatment could effectively slow down MDA production and extend the storage period. Our results are in agreement with findings of other researchers. They reported that steaming can sufficiently inactivate lipase, peroxidase, endoxylanase, and part of the $\alpha$-amylase and making it suitable for possible human consumption [11,37-39]. So steaming was selected as the best treatment for oat bran stabilisation and considered for further long-term storage studies.

3.5. Effect of Heat Treatment on the Sensory Scores of Oat Bran during the Storage Period. As shown in Figure 3, the sensory scores of S-OB during storage were lower than those of the 


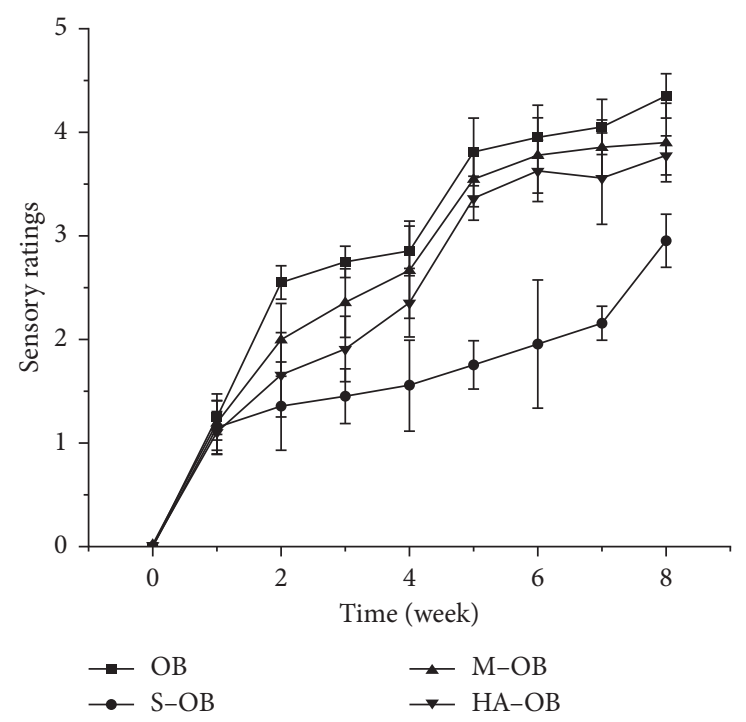

FIGURE 3: Sensory ratings during storage shown by oat bran subjected to different pretreatment methods.
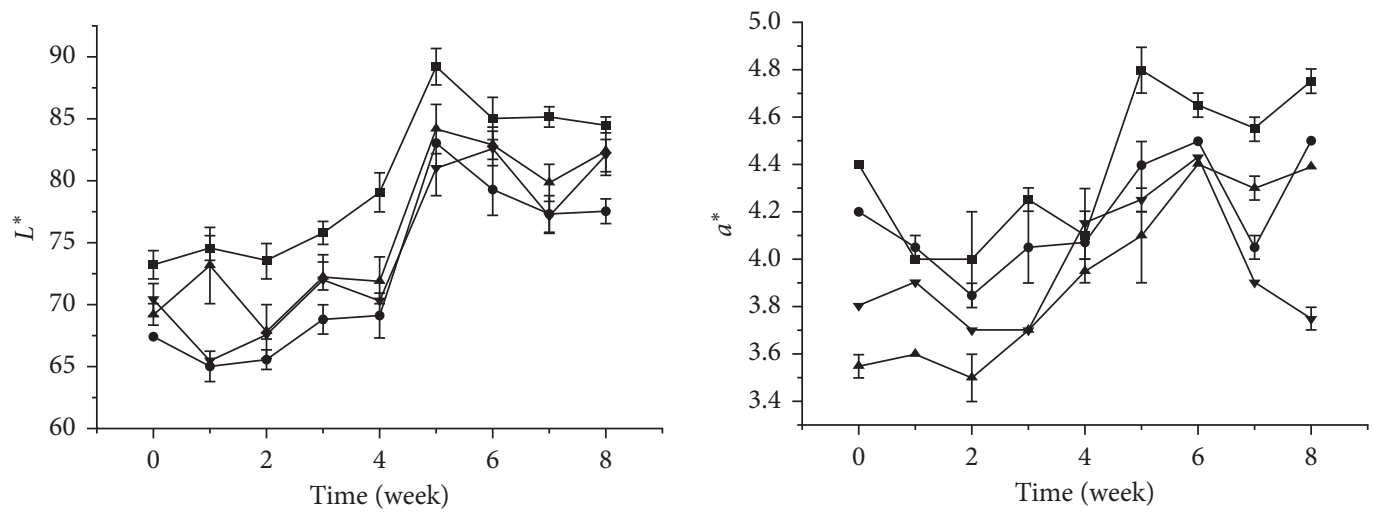

$$
\rightarrow \text { OB } \rightarrow \text { M-OB }
$$$$
\rightarrow-\mathrm{OB}
$$$$
\rightarrow \mathrm{M}-\mathrm{OB}
$$

(a)

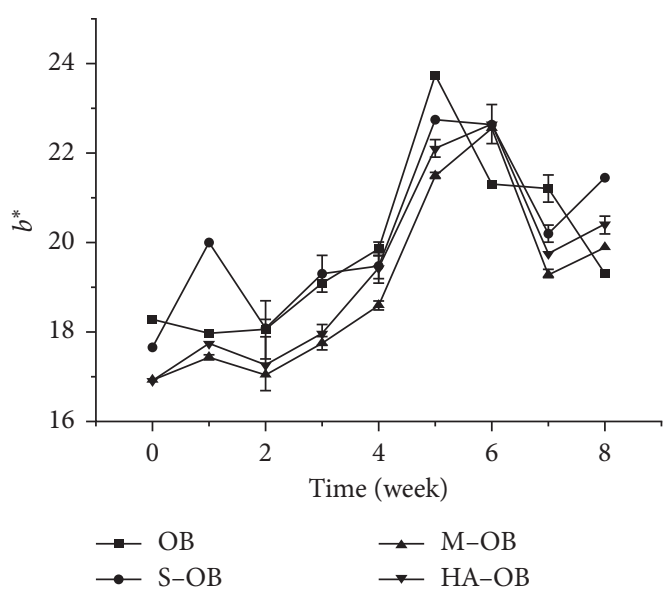

(c)

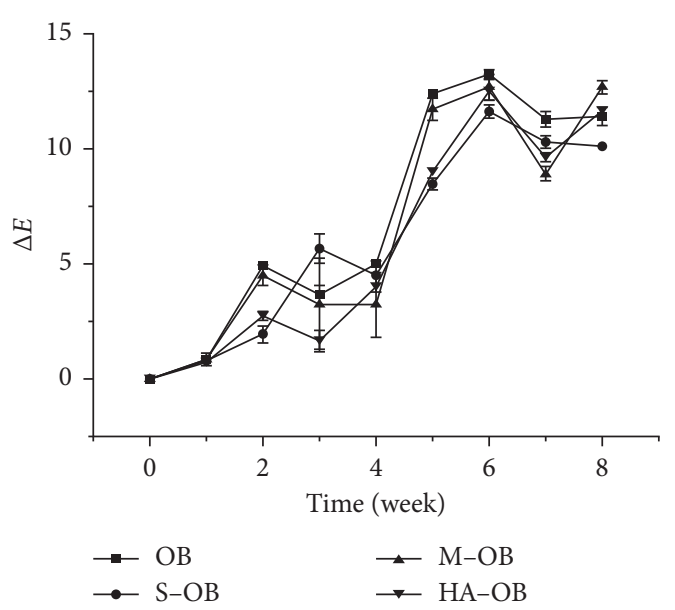

(d)

Figure 4: (a) Changes in $L^{*}$ during storage by oat bran subjected to different heat treatments, (b) changes in $a^{*}$ during storage by oat bran samples subjected to different heat treatments, (c) changes in $b^{*}$ during storage by oat bran subjected to different heat treatments, and (d) changes in $\Delta E$ during storage shown by oat bran subjected to different heat treatments. 
unprocessed samples, indicating that all three heat treatments were effective in inhibiting the souring of oat bran and decelerating the production of harsh flavours and that the sensory scores of steam-treated oat bran were the lowest during storage. Steaming is a more suitable stabilisation treatment than microwaving and hot-air drying. In this study, the sweet, malty flavour of oat bran was most pronounced after steam treatment.

During processing and storage, unsaturated fatty acids and lipids are prone to undergoing oxidation reactions and producing oxidation products, such as aldehydes and ketones, which produce sour tastes and affect the quality and flavour of the products and ultimately sensory scores. Heat treatment can inhibit the enzymatic activities that catalyse the production of harmful substances and undesirable flavours from polyunsaturated fatty acids, such as lipoxygenase, POD, and catalase. A previous study showed that the lipase activity of microwave-treated rice bran is significantly lower than that of unprocessed and steam-treated rice bran $(P<0.05)$, and POD is effectively inactivated [40]. Another study demonstrated that dry heat treatment at $120^{\circ} \mathrm{C}$ for $20 \mathrm{~min}$ delays rancidity and improves flavour [41]. In rice bran, microwaving and steaming inhibit lipase activity and prolong shelf life [42].

\subsection{Effect of Heat Treatment on the Colour Difference of Oat} Bran Storage. The changes in the surface colour $L^{*}, a^{*}, b^{*}$, and $\Delta \mathrm{E}$ values of oat bran during storage are shown in Figure 4 . The brightness $L^{*}$ values of oat bran subjected to different heat treatments increased with storage time and those of S-OB were significantly lower than those of $\mathrm{M}-\mathrm{OB}$ and $\mathrm{HA}-\mathrm{OB}(P<0.05)$. The $L^{*}$ values of $\mathrm{S}-\mathrm{OB}, \mathrm{M}-\mathrm{OB}$, and $\mathrm{HA}-\mathrm{OB}$ were lower than those of untreated oat bran, likely as a result of nonenzymatic browning reactions (e.g., the Merad reaction and caramelisation) that can produce coloured compounds during the initial stages of thermal processing [43]. The $a^{*}$ and $b^{*}$ values of oat bran increased and then decreased with the prolongation of storage time. This trend indicated that the surface colour of oat bran changed from light (white) to dark (black) and then to light (white), from greenish-blue to red-yellow and then to greenish-blue colour as the storage time was extended.

The surface colour difference $\Delta E$ of different heat-treated oat bran samples during storage firstly increased and then decreased with the extension of storage time, and the total colour difference $\Delta E$ was between 0.75 and 12.69. These results, combined with Figure 1, showed that the changes in surface colour during storage were similar to the trends shown by fatty acid values and MDA [44]. Therefore, the surface colour difference indicated that steaming, microwaving, and hot-air drying decelerated the ageing of oat bran and that the steaming treatment was better than the microwave and hot-air drying treatments.

\section{Conclusion}

This experiment clarified the trends of the effects of three heat treatments, namely, steamy, microwave, and hot-air drying treatments, on the dissolution characteristics, powder fluidity, pasting characteristics, thermodynamic properties, and storage stability of oat bran. Steamy, microwave, and hot-air drying treatments improved the solubility of oat bran and had no significant effect on powder fluidity $(P<0.05)$.

After steaming treatment, oat bran showed significantly reduced peak viscosity, trough viscosity, breakdown value, final viscosity, and setback value and significantly improved thermal stability $(P<0.05)$. The stabilisation effect of steaming treatment was better than that of the microwave and hot-air drying treatments. Steaming, microwave, and hot-air drying all increased $T_{0}$ and $T_{\mathrm{P}}$ of oat bran, and the steam-treated oat bran showed improved paste enthalpy and thermal stability.

During 56 days of accelerated storage, the fatty acid values, MDA values, sensory scores, and $L^{*}, a^{*}$, and $b^{*}$ values of oat bran subjected to steaming, microwaving, and hot-air drying treatments showed an overall increasing trend, and the fatty acid values and MDA values of the treated oat bran samples were lower than those of OB. All three heat treatments significantly improved the storage stability of oat bran, delaying the quality deterioration caused by oil oxidation during storage and improving the storage life of oat bran. Through the above study, steamy treatment was considered more advantageous than the other methods.

\section{Abbreviations}

OB: Oat bran

S-OB: Steaming-stabilised oat bran

M-OB: Microwave-stabilised oat bran

HA-WB: Hot-air-stabilised oat bran.

\section{Data Availability}

The data used to support the findings of this study are available from the author upon request.

\section{Additional Points}

(i) Steam-treated oat bran significantly improved the thermal stability $(P<0.05)$.

(ii) All three heat treatments could improve the storage stability and the quality deterioration of oat bran during storage due to oil oxidation. Steaming had the most significant effect.

\section{Conflicts of Interest}

The authors declare that they have no conflicts of interest.

\section{Acknowledgments}

This research was financially supported by the National Natural Science Foundation of China (grant no. 32060515) and Inner Mongolia Autonomous Region Science and Technology Plan Project (No. 2020GG0064). 


\section{References}

[1] A. L. Slater, M. L. Eastridge, J. L. Firkins, and L. J. Bidinger, "Effects of starch source and level of forage neutral detergent fiber on performance by dairy cows," Journal of Dairy Science, vol. 83, no. 2, pp. 313-321, 2000.

[2] M. M.-L. Grundy, J. Quint, A. Rieder et al., "Impact of hydrothermal and mechanical processing on dissolution kinetics and rheology of oat $\beta$-glucan," Carbohydrate Polymers, vol. 166, pp. 387-397, 2017.

[3] T. Ralla, H. Salminen, M. Edelmann, C. Corinna Dawid, T. Hofmann, and J. Weiss, "Oat bran extract (Avena sativa L.) from food by-product streams as new natural emulsifier," Food Hydrocolloids, vol. 81, no. 8, pp. 253-262, 2018.

[4] P. Vitaglione, A. Napolitano, and V. Fogliano, "Cereal dietary fibre: a natural functional ingredient to deliver phenolic compounds into the gut," Trends in Food Science \& Technology, vol. 19, no. 9, pp. 451-463, 2008.

[5] M. Gupta and B. K. Bajaj, "Development of fermented oat flour beverage as a potential probiotic vehicle," Food Bioscience, vol. 20, pp. 104-109, 2017.

[6] A. Asadzadeh, H. Jalali, M. H. Azizi, and A. M. Nafchi, "Production of oat bran functional probiotic beverage using Bifidobacterium lactis," Journal of Food Measurement and Characterization, vol. 15, pp. 1301-1309, 2021.

[7] O. E. C. Doná, B. G. Correa, C. J. Eduardo, K. J. Emy, and P. S. Justina, "Oat bran in cardiovascular risk control in mental disorder," Revista Brasileira de Enfermagem, vol. 73, no. Suppl 1, 2020.

[8] R.-L. Heinio, A. Kaukovirta-Norja, and K. Poutanen, "Flavor in processing new $€$ oat foods," Ceral Food Worlds, vol. 56, no. 1, pp. 21-26, 2011.

[9] M. S. Meera, M. K. Bhashyam, and S. Z. Ali, "Effect of heat treatment of sorghum grains on the storage stability of flour," LWT-Food Science and Technology, vol. 44, no. 10, pp. 2199-2204, 2011.

[10] B. Arns, J. Bartz, M. Radunz et al., "Impact of heat-moisture treatment on rice starch, applied directly in grain paddy rice or in isolated starch," LWT-Food Science and Technology, vol. 60, no. 2, pp. 708-713, 2015.

[11] Y. Hu, L. Wang, and Z. Li, "Superheated steam treatment on wheat bran: enzymes inactivation and nutritional attributes retention," LWT-Food Science and Technology, vol. 91, pp. 446-452, 2018.

[12] O. J. Adebowale, J. Taylor, and H. Kock, "Stabilization of wholegrain sorghum flour and consequent potential improvement of food product sensory quality by microwave treatment of the kernels," LWT-Food Science and Technology, vol. 132, Article ID 109827, 2020.

[13] X. L. Lin, J. Song, X. W. He et al., "Effect of dry heat treatment on the crystal structure and oil absorption of starch in intact kidney bean cells," Modern Food Science and Technology, vol. 35, no. 240(8), pp. 41-47, 2019.

[14] D. R. Benhur, G. Bhargavi, K. Kalpana, A. D. Vishala, K. N. Ganapathy, and J. V. Patil, "Development and standardization of sorghum pasta using extrusion technology," Journal of Food Science and Technology, vol. 52, no. 10, pp. 6828-6833, 2015.

[15] AOCS, Official Methods and Recommended Practices of the America Oil Chemists Society, American Oil Chemists Society, Champaign, IL, USA, 2004.

[16] J. W. Johnston, S. Horne, K. Harding, and E. E. Benson, "Evaluation of the 1-methyl-2-phenylindole colorimetric assay for aldehydic lipid peroxidation products in plants: malondialdehyde and 4-hydroxynonenal," Plant Physiology and Biochemistry, vol. 45, no. 2, pp. 108-112, 2007.

[17] E. Kayitesi, K. G. Duodu, A. Minnaar, and H. L. De Kock, "Sensory quality of marama/sorghum composite porridges," Journal of the Science of Food and Agriculture, vol. 90, no. 12, pp. 2124-2132, 2010.

[18] Z.-H. Zhao, L. Liu, M. Zhang, R. Zhang, J. Xiao, Z. Wei et al., "Effect of pre enzymolysis extrusion on quality characteristics of whole grain brown rice flour," Food science, vol. 40, no. 1, pp. 116-124, 2019.

[19] J. Zhang and M.-L. Zhang, "Effect of ultrahigh-pressure treatment on granule characteristics, thermal properties and rheological properties of oat starch," Food Science, vol. 41, no. 23 , pp. 114-121, 2020.

[20] D. Hu, "Effect of superheated steam on nutritional, physicochemical and storage properties of rice bran," Nanchang University, Nanchang, China, 2018, https://kns.cnki.net/KCMS/detail/ detail.aspx?dbname $=$ CMFD201802\&filename $=1018230981 . \mathrm{nh}$ Master's Thesis.

[21] C. Cao, X. Zhao, C. Zhang, Z. Ding, F. Sun, and C. Zhao, "Effect of inlet temperature on the physicochemical properties of spray-dried seed-watermelon seed protein powder," Journal of Food Science, vol. 85, no. 10, pp. 3442-3449, 2020.

[22] A. M. Bakry, Z. Fang, Y. Ni, H. Cheng, Y. Q. Chen, and L. Liang, "Stability of tuna oil and tuna oil/peppermint oil blend microencapsulated using whey protein isolate in combination with carboxymethyl cellulose or pullulan," Food Hydrocolloids, vol. 60, pp. 559-571, 2016.

[23] X. Sun, R. G. Cameron, and J. Bai, "Effect of spray-drying temperature on physicochemical, antioxidant and antimicrobial properties of pectin/sodium alginate microencapsulated carvacrol," Food Hydrocolloids, vol. 100, Article ID 105420, 2020.

[24] Q. Liu, E. Donner, Y. Yin, R. L. Huang, and M. Z. Fan, "The physicochemical properties and in vitro digestibility of selected cereals, tubers and legumes grown in China," Food Chemistry, vol. 99, no. 3, pp. 470-477, 2006.

[25] E. R. Zavareze, C. R. Storck, L. A. S. Castro, M. A. Schirmer, and A. R. G. Dias, "Effect of heat-moisture treatment on rice starch of varying amylose content," Food Chemistry, vol. 121, no. 2, pp. 358-365, 2010.

[26] D. L. W. Smith, Heat and Mass Transfer in Parboiled Rice During Heating with $915 \mathrm{MHz}$ Microwave Energy and Impacts on Milled Rice Properties, University of Arkansas, Fayetteville, Arkansas, 2020.

[27] X. Chen, X. He, X. Fu, and Q. Huang, "In vitro digestion and physicochemical properties of wheat starch/flour modified by heat-moisture treatment," Journal of Cereal Science, vol. 63, pp. 109-115, 2015.

[28] J. Zhang and M.-L. Zhang, "Progress of research on the effect of superheated treatment on grain starch," Chinese Journal of Cereals and Oils, vol. 35, no. 7, pp. 172-179, 2020.

[29] Z. H. Lu, E. Donner, R. Y. Yada, and Q. Liu, "Physicochemical properties and in vitro starch digestibility of potato starch/ protein blends," Carbohydrate Polymers, vol. 154, pp. 214222, 2016.

[30] H. Wang, Y. Liu, C. Ling, X. Li, J. Wang, and F. Xie, "Insights into the multi-scale structure and digestibility of heatmoisture treated rice starch," Food Chemistry, vol. 242, pp. 323-329, 2018.

[31] M. N. Lavanya, K. C. S. Saikiran, and N. Venkatachalapathy, "Stabilization of rice bran milling fractions using microwave heating and its effect on storage," Journal of Food Science and Technology, vol. 56, no. 2, pp. 889-895, 2019. 
[32] K. Satou, Y. Takahashi, and Y. Yoshii, "Effect of superheated steam treatment on enzymes related to lipid oxidation of brown rice,” 新潟県農業総合研究所食品研究センター研 究報告, vol. 16, no. 1, pp. 93-97, 2013.

[33] C. Brennan, M. Brennan, E. Derbyshire, and B. K. Tiwari, "Effects of extrusion on the polyphenols, vitamins and antioxidant activity of foods," Trends in Food Science \& Technology, vol. 22, no. 10, pp. 570-575, 2011.

[34] D. J. Rose, L. V. Ogden, M. L. Dunn, and O. A. Pike, "Enhanced lipid stability in whole wheat flour by lipase inactivation and antioxidant retention," Cereal Chemistry, vol. 85, no. 2, pp. 218-223, 2008.

[35] W. Wu, Q. Lin, Y. Hua, Y. Wu, Y. Liang, X. Fu et al., "Study on mechanism of soy protein oxidation induced by lipid peroxidation products," Advance Journal of Food Science \& Technology, vol. 5, no. 1, pp. 46-53, 2013.

[36] L. Gong, L. Huang, and Y. Zhang, "Effect of steam explosion treatment on barley bran phenolic compounds and antioxidant capacity," Journal of Agricultural and Food Chemistry, vol. 60, no. 29, pp. 7177-7184, 2012.

[37] J. Almeida, B. Pareyt, L. R. Gerits, and J. A. Delcour, "Effect of wheat grain steaming and washing on lipase activity in whole grain flour," Cereal Chemistry, vol. 91, no. 4, pp. 321-326, 2014.

[38] D. S. Head, S. Cenkowski, S. Arntfield, and K. Henderson, "Superheated steam processing of oat groats," LWT-Food Science and Technology, vol. 43, no. 4, pp. 690-694, 2010.

[39] L. Liu, M. Zhao, X. Liu et al., "Effect of steam explosionassisted extraction on phenolic acid profiles and antioxidant properties of wheat bran," Journal of the Science of Food \& Agriculture, vol. 96, no. 10, pp. 3484-3491, 2016.

[40] P. Sharma, N. Sharma, S. Pathania, and S. Handa, "Purification and characterization of lipase by Bacillus methylotrophicus PS3 under submerged fermentation and its application in detergent industry," Journal of Genetic Engineering \& Biotechnology, vol. 15, no. 2, pp. 369-377, 2017.

[41] S. W. Lv, L. Y. He, and L. H. Sun, "Effect of different stabilisation treatments on preparation and functional properties of rice bran proteins," Czech Journal of Food Sciences, vol. 36, no. 1, pp. 57-65, 2018.

[42] N. N. A. M. Nordin, R. Karim, H. M. Ghazali, N. M. Adzahan, and M. T. Sultan, "Effects of various stabilization techniques on the nutritional quality and antioxidant potential of brewer's rice," Journal of Engineering Science \& Technology, vol. 9, no. 3, pp. 347-363, 2014.

[43] R. Raghunathan, R. Hoover, R. Waduge, Q. Liu, and T. D. Warkentin, "Impact of molecular structure on the physicochemical properties of starches isolated from different field pea (Pisum sativum L.) cultivars grown in Saskatchewan, Canada," Food Chemistry, vol. 221, no. 2, pp. 1514-1521, 2017.

[44] X. Huang, W. Li, H. Zhou et al., "Study on the change law of rice storage quality in warehouse J/OL," Chinese Journal of Cereals and Oils, pp. 1-7, 2021, http://kns.cnki.net/kcms/ detail/11.2864.TS.20210416.1633.044.html. 